\title{
A novel TBX20 loss-of-function mutation contributes to adult-onset dilated cardiomyopathy or congenital atrial septal defect
}

\author{
YI-MENG ZHOU $^{1 *}$, XIAO-YONG DAI ${ }^{1 *}$, RI-TAI HUANG ${ }^{2}$, SONG XUE $^{2}$, \\ YING-JIA XU ${ }^{3}$, XING-BIAO QIU ${ }^{3}$ and YI-QING YANG $^{3-5}$ \\ ${ }^{1}$ Department of Emergency Medicine, Yangpu Hospital, Tongji University School of Medicine, Shanghai 200090; \\ ${ }^{2}$ Department of Cardiovascular Surgery, Renji Hospital, School of Medicine, Shanghai Jiao Tong University, Shanghai 200127; \\ Departments of ${ }^{3}$ Cardiology, ${ }^{4}$ Cardiovascular Research Laboratory and ${ }^{5}$ Central Laboratory, \\ Shanghai Chest Hospital, Shanghai Jiao Tong University, Shanghai 200030, P.R. China
}

Received July 11, 2015; Accepted July 22, 2016

DOI: $10.3892 / \mathrm{mmr} .2016 .5609$

\begin{abstract}
Dilated cardiomyopathy (DCM) is the most prevalent form of primary cardiomyopathy in humans and is a leading cause of heart failure and sudden cardiac death. Genetic abnormalities have been demonstrated to be a major contributor to the development of DCM. However, DCM is a genetically heterogeneous disease, and the genetic basis underlying DCM in a significant proportion of patients remains unclear. In the current study, the coding exons and splicing junction sites of the T-Box 20 (TBX20) gene, which encodes a T-box transcription factor essential for cardiac morphogenesis and structural remodeling, were sequenced in 115 unrelated patients with idiopathic DCM, and a novel heterozygous mutation, p.E143X, was identified in one patient. Genetic analysis of the mutation carrier's pedigree indicated that the nonsense mutation was present in all the living family members with DCM, and also in a female patient with a congenital atrial septal defect. The mutation, which was predicted to generate a truncated protein with only the $\mathrm{N}$-terminus and a fraction of the T-box domain remaining, was absent in 800 control chromosomes. Functional assays using a dual-luciferase reporter assay system revealed that the truncated TBX20 protein had no
\end{abstract}

Correspondence to: Dr Yi-Meng Zhou, Department of Emergency Medicine, Yangpu Hospital, Tongji University School of Medicine, 450 Tengyue Road, Shanghai 200090, P.R. China

E-mail: yimengzhou@163.com

Dr Yi-Qing Yang, Department of Cardiovascular Research Laboratory, Shanghai Chest Hospital, Shanghai Jiao Tong University, 241 West Huaihai Road, Shanghai 200030, P.R. China

E-mail: dryyq@tongji.edu.cn

${ }^{*}$ Contributed equally

Key words: dilated cardiomyopathy, genetics, transcriptional factor, TBX20, reporter gene assay transcriptional activity in contrast to its wild-type counterpart. Furthermore, the mutation abolished the synergistic activation between TBX20 and NK2 homeobox 5, or between TBX20 and GATA binding protein 4 . The observations of the current study expand the mutation spectrum of TBX20 associated with DCM and congenital heart disease (CHD), which provide novel insight into the molecular mechanisms underlying DCM and CHD, suggesting the potential implications for the effective and personalized treatment of these diseases.

\section{Introduction}

Dilated cardiomyopathy (DCM) is a heart muscle disease characterized by ventricular chamber enlargement and contractile dysfunction with normal left ventricular wall thickness (1). It is the most common form of primary cardiomyopathy, affecting approximately 1 in 2,500 individuals worldwide (1). DCM may give rise to congestive heart failure, ventricular and supraventricular arrhythmias, cardiac conduction blocks, thromboembolism and sudden cardiac death. DCM is the third most common cause of heart failure and the most frequent reason for requiring heart transplantation $(1,2)$. Accumulating evidence demonstrates that genetic risk factors serve a crucial role in the pathogenesis of familial DCM, which can be inherited in an autosomal dominant, autosomal recessive, X-linked, or mitochondrial pattern, with the pattern of autosomal dominant inheritance present in greater than $90 \%$ of patients $(3,4)$. At present, $>50$ genes have been associated with familial or sporadic DCM (4-9). The majority of these DCM-associated genes encodes for sarcomeric proteins in addition to cytoskeletal proteins, including contractile elements, sarcolemma elements, Z-disc elements and Z-I region components, which are responsible for the generation and transmission of contractile force $(4,7)$. However, these known DCM-causing genes only account for approximately a third of patients with DCM and furthermore, the majority of these have a low mutation frequency, occurring in $<1 \%$ of patients with DCM (10). Thus, the identification of novel genetic defects underpinning DCM is required in order to fully elucidate the molecular mechanisms of DCM. 
Previously, numerous key cardiac transcription factors, including homeobox protein NK2 homeobox 5 (NKX2-5), zinc finger proteins GATA binding protein 4 (GATA4), GATA5 and GATA6, and T-box factors T-Box 5 (TBX5) and TBX20, have been demonstrated to physically interact with each other to mediate embryonic cardiogenesis and adult cardiac remodeling (11-18). In addition, mutations in these core cardiac transcription factors have been causally associated with various congenital heart diseases (CHD) and cardiac arrhythmias (19-40). Of note, mutations in NKX2-5, GATA4, GATA5, GATA6 and TBX5 have additionally been associated with DCM in humans (41-49). Given that the expression profile and functional characteristics of $T B X 20$ overlap at least partially with those of NKX2-5, GATA4, GATA5, GATA6 and $T B X 5$ (13-15,18,50), it is suggested that mutations in $T B X 20$ may contribute to DCM in a subset of patients.

\section{Materials and methods}

Study subjects. In the current case-control study, 115 unrelated patients (65 males and 50 females, mean age of 52 years) with idiopathic DCM were enrolled from a Han Chinese population, with 400 ethnically-matched (228 males and 172 females, mean age of 52 years), unrelated healthy individuals recruited as controls. The 14 available family members of the index patient carrying an identified TBX20 mutation were also included. The participants of the present study were recruited from Yangpu Hospital, Renji Hospital, Shanghai Jiao Tong University and Shanghai Chest Hospital (Shanghai, China), during between January 2013 and December 2014. All study participants were clinically evaluated by medical history, physical examination, echocardiography, electrocardiogram and exercise performance testing. Cardiac catheterization, coronary angiography, myocardial biopsy or cardiac magnetic resonance imaging were performed only if there was a strong indication for the corresponding procedure. Diagnosis of idiopathic DCM was made as described previously: Left ventricular end-diastolic diameter $>27 \mathrm{~mm} / \mathrm{m}^{2}$ and an ejection fraction $<40 \%$ or fractional shortening $<25 \%$ in the absence of underlying conditions including ischemic heart disease, hypertension, CHD, valvular heart disease, myocarditis and metabolic disorders (42-49). The current study was conducted in line with the principles of the Declaration of Helsinki. The study protocol was approved by the ethics committee of Yangpu Hospital (Tongji University School of Medicine, Shanghai, China) and written informed consent was obtained by all participants prior to investigation.

Genetic scan of TBX20. Peripheral venous blood samples were obtained by using syringe from antecubital veins of all study subjects. Genomic DNA was isolated from blood cells with the Wizard Genomic DNA Purification kit (Promega Corporation, Madison, WI, USA). The coding exons and flanking introns of the TBX20 gene were sequenced in 115 unrelated patients with sporadic DCM, in addition to in 200 control individuals. The primer pairs used to genotype $T B X 20$ by polymerase chain reaction (PCR)-sequencing were designed as previously described (32). PCR was performed using HotStar Taq DNA Polymerase (Qiagen GmbH, Hilden, Germany) on a Veriti Thermal Cycler (Applied Biosystems; Thermo Fisher
Scientific, Inc., Waltham, MA, USA) with standard conditions and concentrations of reagents (27). Both strands of each PCR product were sequenced with a BigDye ${ }^{\circledR}$ Terminator v3.1 Cycle Sequencing kit (Applied Biosystems; Thermo Fisher Scientific, Inc.) on an ABI PRISM 3130 XL DNA Analyzer (Applied Biosystems; Thermo Fisher Scientific, Inc.). DNA sequences were analyzed with DNA Sequencing Analysis software, version 5.1 (Applied Biosystems; Thermo Fisher Scientific, Inc.). A variant was confirmed by re-sequencing of an independent PCR-generated amplicon from the same subject. For each identified sequence variant, the single nucleotide polymorphism (SNP; http://www.ncbi.nlm.nih.gov/SNP) database and human gene mutation database (HGMD; http://www.hgmd.org) were searched for its novelty.

Prediction of the disease-causing potential of a TBX20 sequence variation. The causative potential of a TBX20 sequence variation was predicted using MutationTaster (http://www.mutationtaster.org), which produced the probability for the variation to be either a pathogenic mutation or a benign polymorphism. Notably, the given P-value was the probability of the correct prediction rather than the probability of error as used in t-test statistics. Thus, a value close to 1 indicates a high accuracy of prediction.

Expression plasmids and site-directed mutagenesis. The recombinant expression plasmid TBX20-pcDNA3.1 was constructed as described previously (32). The expression plasmids GATA4-pSSRa and NKX2-5-pEFSA, and the reporter plasmid ANF-luciferase (ANF-luc), which contains the 2600-bp 5'-flanking region of the $A N F$ gene and expresses Firefly luciferase, were provided by Dr Ichiro Shiojima from Chiba University School of Medicine (Chiba, Japan). The identified mutation was introduced into the wild-type TBX20-pcDNA3.1 construct by site-directed mutagenesis using the QuikChange II XL Site-Directed Mutagenesis kit (Stratagene; Agilent Technologies, Inc., Santa Clara, CA, USA) and a complementary pair of primers (F: 5'-TCGGGG GTGGATCCTTAGGCCAAGTACATAG-3'; R: 5'-CTATGT ACTTGGCCTAAGGATCCACCCCCGA-3'). The mutant was sequenced to confirm the desired mutation and to exclude any other sequence variations.

Cell culture and reporter gene assays. COS-7 cells were grown in 6-well plates in Dulbecco's modified Eagle's medium supplemented with $10 \%$ fetal calf serum and maintained in an atmosphere of $10 \% \mathrm{CO}_{2}$ at $37^{\circ} \mathrm{C}$. Transfections of COS-7 cells were conducted at approximately $90 \%$ confluency with Lipofectamine ${ }^{\text {TM }} 2000$ reagent (Invitrogen; Thermo Fisher Scientific, Inc.). In cell transfection experiments, $0.8 \mu \mathrm{g}$ wild-type TBX20-pcDNA3.1, $0.8 \mu \mathrm{g}$ E143X-mutant TBX20-pcDNA3.1, $0.4 \mu \mathrm{g}$ wild-type TBX20-pcDNA3.1 or $0.4 \mu \mathrm{g}$ wild-type TBX20-pcDNA3.1 together with $0.4 \mu \mathrm{g}$ E143X-mutant TBX20-pcDNA3.1 was used, in combination with $1.0 \mu \mathrm{g}$ ANF-luc and $0.04 \mu \mathrm{g}$ pGL4.75 (Promega Corporation). In order to investigate the ability of the mutant TBX20 to activate the ANF gene synergistically with NKX2-5 or GATA4, the same quantity $(0.6 \mu \mathrm{g})$ of expression plasmid DNA (empty pcDNA3.1, wild-type TBX20-pcDNA3.1, NKX2-5-pEFSA, GATA4-pSSRa or 
E143X-mutant TBX20-pcDNA3.1) was used alone or together, in the presence of $1.0 \mu \mathrm{g}$ ANF-luc and $0.04 \mu \mathrm{g}$ pGL4.75. The empty expression vector plasmid pcDNA3.1 was used as a negative control. The internal control reporter vector pGL4.75 expressing Renilla luciferase was used to normalize transfection efficiency. Cells were harvested and lysed $36 \mathrm{~h}$ subsequent to transfection. Luciferase assays were performed using a Dual-Glo luciferase assay kit (Promega Corporation) according to the manufacturer's protocol. The results were expressed as fold activity of Firefly luciferase relative to Renilla luciferase. A total of 14 separate transfection experiments were conducted, and for each experiment, transfections were performed in triplicate.

Statistical analysis. Data are presented as the mean \pm standard deviation. Continuous variables were compared between two groups using student's unpaired t-test. Comparison of the categorical variables between two groups was performed using Pearson's $\chi^{2}$ test. Two-tailed $\mathrm{P}<0.05$ was considered to indicate a statistically significant difference.

\section{Results}

Baseline clinical characteristics of the study subjects. A cohort of 115 unrelated patients with sporadic DCM underwent clinical investigation in contrast to a total of 400 unrelated control individuals. None of them had other identifiable risk factors for DCM. All the patients developed DCM when they were reached adulthood. The average age of onset of DCM was $43 \pm 8$ years, with a median of 43 years. The control individuals had no evidence of cardiac structural abnormality or functional impairment, and their echocardiographic results were normal. There was no significant difference in the age, gender and body-mass index between the case and control groups $(\mathrm{P}>0.05)$. Compared with those in the control group, in the patient group the arterial blood pressure levels and left ventricular ejection fraction were significantly reduced $(\mathrm{P}<0.05)$, whereas the heart rate, left ventricular end-diastolic diameter and left ventricular end-systolic diameter were significantly increased $(\mathrm{P}<0.05)$. The baseline clinical characteristics of the study subjects are summarized in Table I.

TBX20 mutation. By direct sequencing of TBX20, a heterozygous mutation was identified in one of 115 unrelated patients with sporadic DCM, with a mutational prevalence of nearly $0.87 \%$. Specifically, a transition of guanine $(G)$ to thymine (T) in the first nucleotide of codon 143 (c. $427 \mathrm{G}>\mathrm{T})$, resulting in a substitution of stop codon for glutamic acid codon at amino acid position 143 (p.E143X), was identified in an index patient. The sequence chromatograms demonstrating the heterozygous TBX20 mutation and its wild-type control sequence are presented in Fig. 1A. A schematic diagram of the TBX20 protein depicting the structural domains and location of the mutation identified in the present study is presented in Fig. 1B. The nonsense mutation was neither observed in the 400 control individuals nor in the SNP and HGM databases. Genetic screening of the proband's available family members demonstrated that the mutation was present in all family members affected with DCM, which was transmitted in an autosomal dominant pattern in the family. However, all the
Table I. Baseline clinical characteristics of the patients with DCM and control individuals.

\begin{tabular}{lccc}
\hline Parameters & $\begin{array}{c}\text { Patients } \\
(\mathrm{n}=115)\end{array}$ & $\begin{array}{c}\text { Controls } \\
(\mathrm{n}=400)\end{array}$ & P-value \\
\hline Age (years) & $52 \pm 14$ & $52 \pm 12$ & 1.0000 \\
Male & $65(57)$ & $228(57)$ & 0.9273 \\
BMI $\left(\mathrm{kg} / \mathrm{m}^{2}\right)$ & $23 \pm 5$ & $23 \pm 6$ & 1.0000 \\
SBP $(\mathrm{mmHg})$ & $116 \pm 17$ & $128 \pm 15$ & $<0.0001$ \\
DBP $(\mathrm{mmHg})$ & $72 \pm 10$ & $84 \pm 9$ & $<0.0001$ \\
HR (bpm) & $82 \pm 15$ & $74 \pm 11$ & $<0.0001$ \\
LVEDD (mm) & $68 \pm 8$ & $47 \pm 6$ & $<0.0001$ \\
LVESD (mm) & $55 \pm 6$ & $34 \pm 5$ & $<0.0001$ \\
LVEF $(\%)$ & $37 \pm 11$ & $62 \pm 8$ & $<0.0001$ \\
NYHA function class & & & \\
I & $11(10)$ & NA & NA \\
II & $29(25)$ & NA & NA \\
III & $52(45)$ & NA & NA \\
IV & $23(20)$ & NA & NA \\
Medicine & & & \\
ACEI & $71(62)$ & NA & NA \\
ARB & $22(19)$ & NA & NA \\
$\beta$-blockers & $67(58)$ & NA & NA \\
Diuretics & $95(83)$ & NA & NA \\
Digitalis & $86(75)$ & NA & NA \\
\hline
\end{tabular}

Data were given as mean \pm standard deviation or number $(\%)$. DCM, dilated cardiomyopathy; BMI, body-mass index; SBP, systolic blood pressure; DBP, diastolic blood pressure; HR, heart rate; LVEDD, left ventricular end-diastolic diameter; LVESD, left ventricular end-systolic diameter; LVEF, left ventricular ejection fraction; NYHA, New York Heart Association; ACEI, angiotensin-converting enzyme inhibitor; ARB, angiotensin receptor blocker; NA, not applicable or not available.

DCM-affected family members appeared healthy when they were juveniles. Additionally, the proband's sister (II-6) additionally presented with congenital atrial septal defect (ASD) and her juvenile daughter (III-3) only presented with ASD. The pedigree structure of the family is illustrated in Fig. 1C. The phenotypic characteristics and mutation status of the affected family members are presented in Table II.

Disease-causing potential of the TBX20 variation. The TBX20 sequence variation of $\mathrm{c} .427 \mathrm{G}>\mathrm{T}$ was predicted by MutationTaster to be a pathogenic mutation, with a P-value of 1 .

Diminished transcriptional activity of the mutant TBX20 protein. As presented in Fig. 2, the same amount $(0.8 \mu \mathrm{g})$ of wild-type TBX20 and E143X-mutant TBX20 activated the ANF promoter by $\sim 11$-fold and $\sim 1$-fold, respectively (wild type vs. mutant: $\mathrm{t}=11.7530, \mathrm{P}=0.0003)$. When $0.4 \mu \mathrm{g}$ wild-type TBX20 was transfected alone or together with $0.4 \mu \mathrm{g}$ E143X-mutant TBX20, the induced activation of the $A N F$ promoter was $\sim 6$-fold (wild type vs. wild type plus mutant: $\mathrm{t}=4.5758$, $\mathrm{P}=0.0102$ ). These results demonstrate that the mutant TBX20 
Table II. Phenotypic characteristics and TBX20 mutation status of the affected family members.

\begin{tabular}{lccccccccc}
\hline Individual & Gender & $\begin{array}{c}\text { Age } \\
\text { (years) }\end{array}$ & $\begin{array}{c}\text { Cardiac } \\
\text { phenotype }\end{array}$ & $\begin{array}{c}\text { LVEDD } \\
(\mathrm{mm})\end{array}$ & $\begin{array}{c}\text { LVESD } \\
(\mathrm{mm})\end{array}$ & $\begin{array}{c}\text { LVEF } \\
(\%)\end{array}$ & $\begin{array}{c}\text { LVFS } \\
(\%)\end{array}$ & $\begin{array}{c}\text { ECG } \\
\text { findings }\end{array}$ & $\begin{array}{c}\text { TBX20 } \\
\text { mutation } \\
(\text { E143X) }\end{array}$ \\
\hline I-1 & M & 68 & DCM & 56 & 65 & 26 & 14 & AVB, PVC & $+/-$ \\
II-3 & M & 44 & DCM & 45 & 58 & 32 & 23 & & $+/-$ \\
II-6 & F & 39 & DCM, ASD & 47 & 55 & 36 & 15 & AVB & $+/-$ \\
III-2 & F & 22 & DCM & 43 & 54 & 48 & 21 & & +- \\
III-3 & F & 14 & ASD & 37 & 25 & 65 & 32 & IRBBB & $+/-$ \\
\hline
\end{tabular}

TBX20, T-Box 20; M, male; F, female; DCM, dilated cardiomyopathy; ASD, atrial septal defect; LVEDD, left ventricular end-diastolic diameter; LVESD, left ventricular end-systolic diameter; LVEF, left ventricular ejection fraction; LVFS, left ventricular fractional shortening; ECG, electrocardiogram; AVB, atrioventricular conduction block; PVC, premature ventricular contraction; IRBBB, incomplete right bundle branch block; +/-, heterozygote.

A
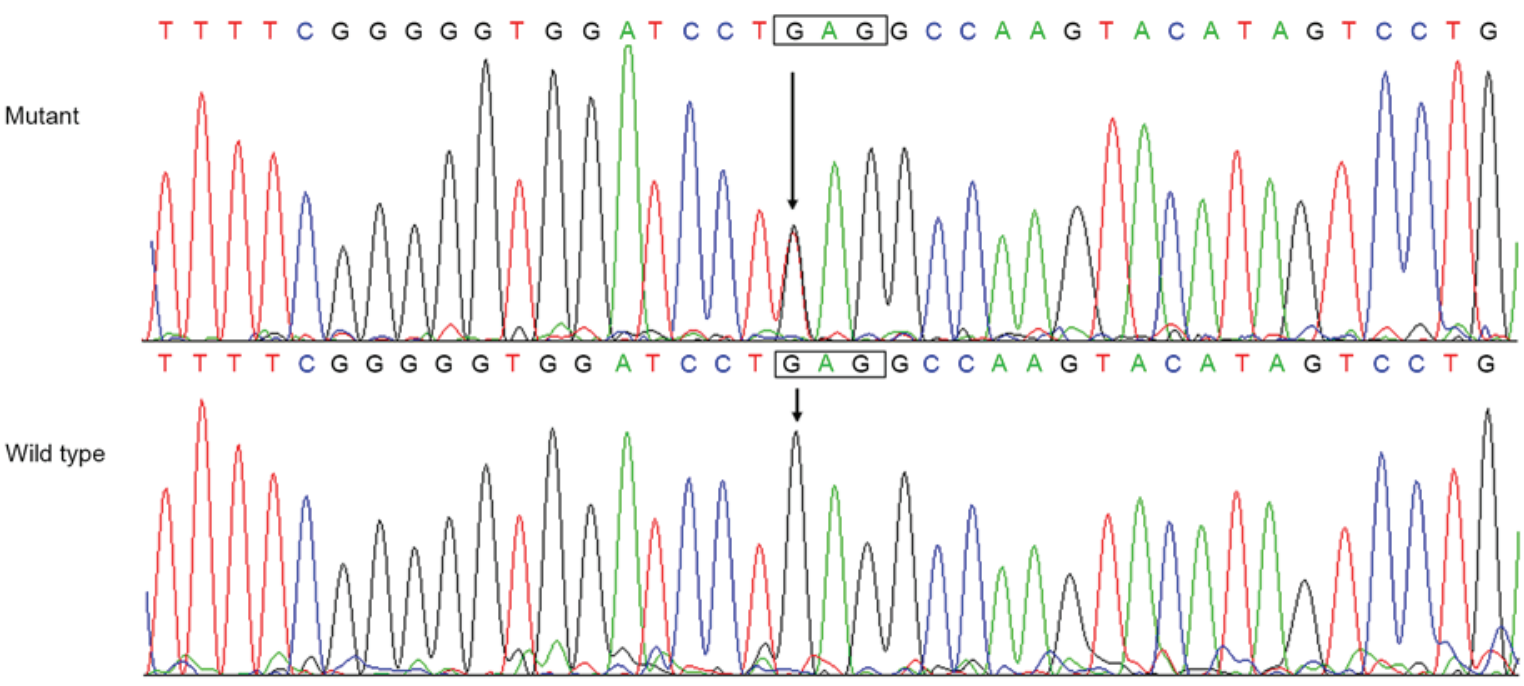

$\mathbf{B}$

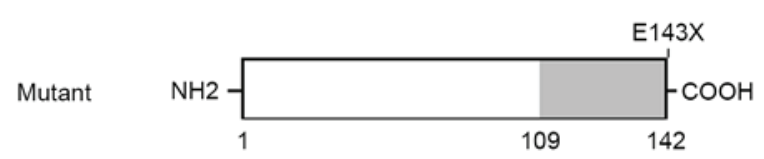

Wild type

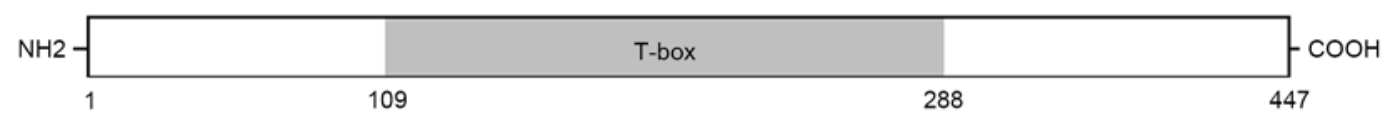

C

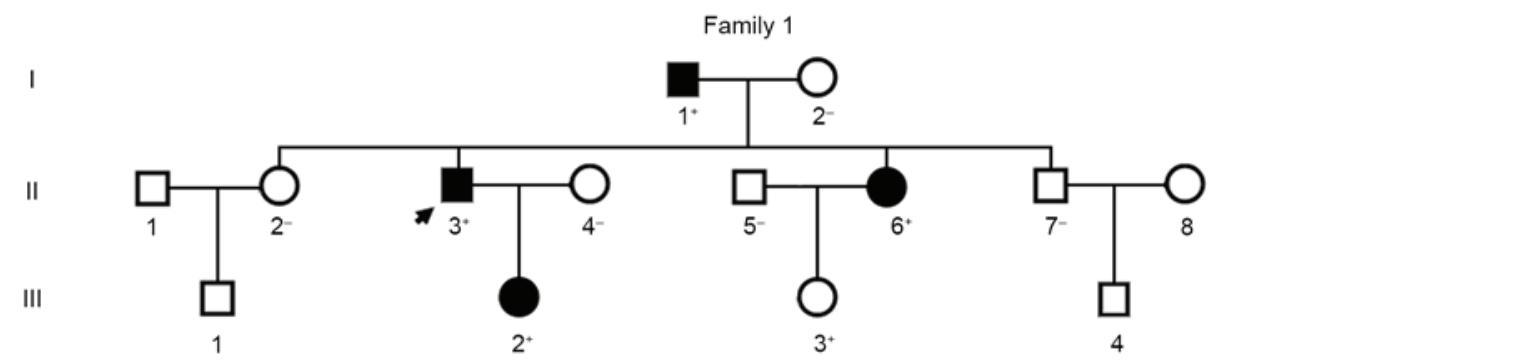

Figure 1. Novel TBX20 mutation associated with adult-onset dilated cardiomyopathy or congenital atrial septal defect. (A) Sequence electropherograms showing the heterozygous TBX20 mutation and its normal control. The arrow points to the heterozygous nucleotides of G/T in the proband (mutant) or the homozygous nucleotides of $\mathrm{G} / \mathrm{G}$ in a control individual (wild type). The rectangle marks the nucleotides that comprise a codon of TBX20. (B) Schematic diagrams of the structures of the full-length and truncated TBX20 proteins. The mutation identified in patients with dilated cardiomyopathy or congenital atrial septal defect is presented above the truncated T-box structural domain (mutant). NH2 indicates amino-terminus; COOH, carboxyl-terminus. (C) Pedigree structure of the family with dilated cardiomyopathy or atrial septal defect. The family was designated as family 1 and the family members are identified by generations and numbers. Squares indicate male family members; circle, female member; closed symbol, affected member; open symbol, unaffected member; arrow, proband; '+', carrier of the heterozygous mutation; and '-', non-carrier. TBX20, T-box 20. 


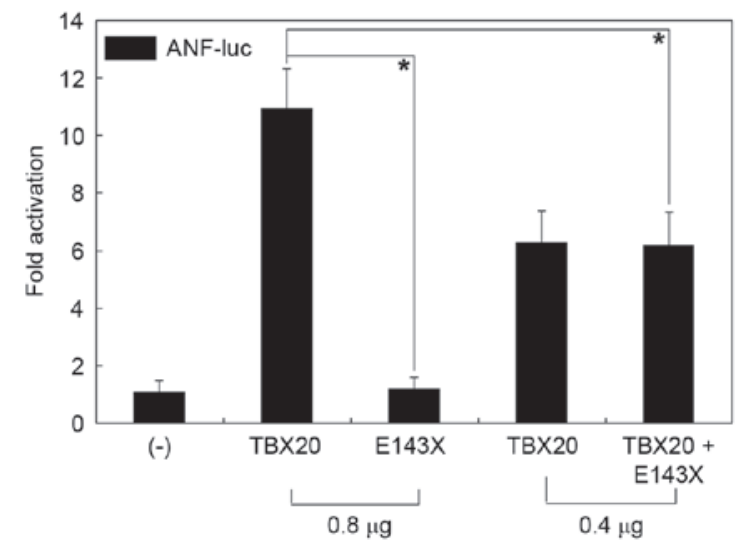

Figure 2. Transcriptional functional failure caused by TBX20 mutations Activation of ANF-luc reporter in COS-7 cells with wild-type TBX20 or mutant TBX20 (E143X), alone or in combination, exhibited no transcriptional activity or dominant-negative effects by the mutant protein. Experiments were performed in triplicate, and the data are presented as the mean \pm standard deviation. ${ }^{*} \mathrm{P}<0.05$, vs. wild-type TBX20. TBX20, T-box 20; ANF, atrial natriuretic factor; luc, luciferase.

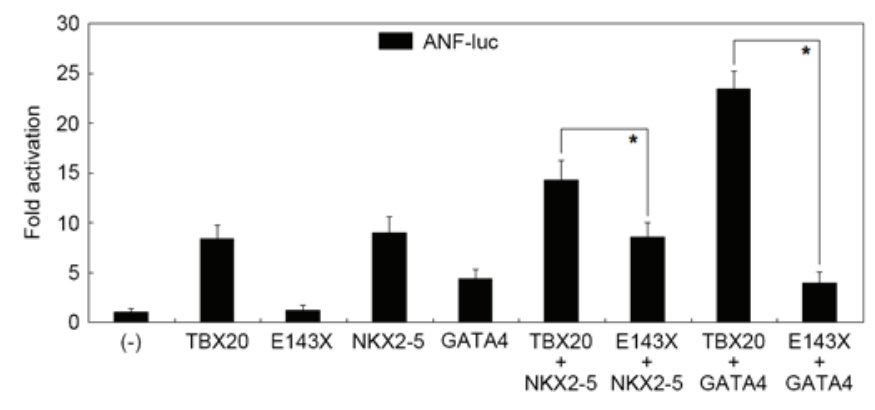

Figure 3. Abolished synergistic activation between mutant TBX20 and NKX2-5 or GATA4. The synergistic activation of the ANF promoter in COS-7 cells by TBX20 and NKX2-5 or GATA4 was abolished by the mutation. Experiments were performed in triplicate, and the data is presented as the mean \pm standard deviation. ${ }^{*} \mathrm{P}<0.05$, vs. wild-type as indicated. TBX20, T-box 20; NKX2-5, NK2 homeobox 5; GATA4, GATA binding protein 4; $\mathrm{ANF}$, atrial natriuretic factor; luc, luciferase.

lacks transactivational activity and has no dominant-negative effect on wild-type TBX20.

Disrupted synergistic transactivation between mutant TBX20 and NKX2-5 or GATA4. As presented in Fig. 3, in the presence of $0.6 \mu \mathrm{g}$ wild-type NKX2-5, the same amount $(0.6 \mu \mathrm{g})$ of wild-type and E143X-mutant TBX20 activated the ANF promoter by $\sim 14$-fold and $\sim 9$-fold, respectively (wild type vs. mutant in the presence of NKX2-5: $\mathrm{t}=4.1650, \mathrm{P}=0.0141$ ); while in the presence of $0.6 \mu \mathrm{g}$ wild-type GATA4, the same amount $(0.6 \mu \mathrm{g})$ of wild-type and E143X-mutant TBX20 activated the $A N F$ promoter by $\sim 23$-fold and $\sim 4$-fold, respectively (wild type vs. mutant in the presence of GATA4: $\mathrm{t}=16.3428, \mathrm{P}<0.0001)$. These data indicate that the E143X-mutant TBX20 fails to transactivate the $A N F$ promoter in synergy with NKX2-5 or GATA4.

\section{Discussion}

In the current study, a novel heterozygous TBX20 mutation of p.E143X was identified in a family with DCM or ASD. The nonsense mutation, which was predicted to be causative by MutationTaster, was absent in the 800 reference chromosomes from an ethnically-matched control population. Functional analyses demonstrated that the mutant TBX20 failed to transcriptionally activate the $A N F$ promoter and exhibited no inhibitory effect on its wild-type counterpart. Furthermore, the mutation disrupted the synergistic activation between TBX20 and NKX2-5 or GATA4. These observations suggest that haploinefficiency resulting from the $T B X 20$ mutation is an alternative mechanism of DCM or CHD in a subset of patients.

In order to maintain the high fidelity of gene expression, cells may utilize multiple decay approaches to eliminate nonfunctional transcripts. At the mRNA level, there are three avenues to protect cells from the possible accumulation of abnormal mRNA and potentially toxic proteins, including non-stop decay, which detects and degrades mRNAs lacking a stop codon, no-go decay, which targets mRNAs with ribosomes arrested in translation elongation, and nonsense-mediated mRNA decay (NMD), which promotes the degradation of mRNAs undergoing premature translation termination (51). The premature termination codon (PTC) is derived from various types of mutations, including nonsense mutations that convert a sense codon into an in-frame PTC, insertion or deletion mutations that alter the ribosomal reading frame, causing translating ribosomes to encounter a PTC, and mutations that result in mRNA splicing defects that lead to retention of an intron altering the reading frame, causing translating ribosomes to encounter a PTC (52). In the current study, the identified nonsense mutation in TBX20 is suggested to induce NMD, resulting in haploinefficiency. However, due to inaccessibility to the mutation carriers' tissue specimens, it was not possible to confirm the absence of the truncated TBX20 protein.

Multiple TBX20 mutations have been previously associated with enhanced vulnerability to DCM in humans. Kirk et al (53) sequenced TBX20 in 352 unrelated patients with CHD and identified two mutations (p.I152 M and p.Q195X) in two index patients with ASD, respectively. Genetic analysis of the two pedigrees indicated that in the family harboring Q195X mutation, there were two living mutation carriers, of whom a female had DCM and mitral valve malformation, and a male had DCM, ASD, coarctation of the aorta and pulmonary hypertension. Functional assays demonstrated that the nonsense mutation led to a loss-of-function effect. Qian et al (54) scanned TBX20 in 96 unrelated DCM patients and identified three mutations (p.L196 V,p.R334Q and p.W349R) in three patients, respectively. However, the functional effect of these DCM-associated mutations remains to be elucidated. Zhao et al (55) screened TBX2O in 120 unrelated patients with idiopathic DCM and identified a mutation (p.F256I) in one patient. Functional analyses indicated that the mutation had a dominant-negative effect. In the present study, a novel TBX20 mutation that caused haploinefficiency was associated with isolated DCM in humans for, to the best of our knowledge, the first time. These results suggest that TBX20 mutations are an uncommon cause for DCM.

The association of the $T B X 20$ loss-of-function mutation with increased susceptibility to DCM may be partially ascribed to the abnormal development and structural remodeling of the heart. In mice, as a transcriptional regulator 
required for cardiac development, $T B \times 20$ served a crucial role in the maintenance of structural and functional phenotypes in adult mouse heart, and homozygous deletion of TBX2O led to embryonic lethality resulting from an underdeveloped heart that was poorly proliferative and lacked myocardial chambers; while adult heterozygous $T B \times 20$-null mice presented with DCM and mild ASD (53). In addition, conditional knockout of TBx20 in adult murine cardiomyocytes resulted in a rapid onset and progression of heart failure, arrhythmias and death (56). In humans and mice during heart failure, TBX20 expression has been reported to be downregulated, accompanied by elevated cardiomyocyte apoptotic levels (57). In cultured neonatal rat cardiomyocytes, $\mathrm{H}_{2} \mathrm{O}_{2}$ was observed to result in a concurrent reduction in TBX20 expression and increase in apoptosis, whereas TBX20 overexpression reduced $\mathrm{H}_{2} \mathrm{O}_{2}$-induced cardiomyocyte apoptosis. In addition, estrogen was able to protect cardiomyocytes from $\mathrm{H}_{2} \mathrm{O}_{2}$-induced apoptosis by upregulating TBX20 expression in a concentration-dependent manner; while TBX20 silencing increased oxidative stress-induced apoptosis in H9c2 cells (57). These experimental observations provide evidence supporting the hypothesis that in humans, genetically defective $T B X 20$ predisposes to DCM.

Previous studies demonstrated that TBX20 transcriptionally activated multiple cardiac target genes, including $A N F, C X 40$ and $S R F$, alone or in synergy with cooperative partners (18), and loss-of-function mutations in several transcriptionally cooperative partners of TBX20, including NKX2-5, GATA4, GATA5, GATA6 and TBX5, have been associated with DCM in humans (41-49). Therefore, TBX20 mutations may enhance vulnerability to DCM, likely by reducing synergistic transactivation of certain target genes key to embryonic cardiogenesis and adult cardiac structure and function.

Notably, multiple TBX20 mutations have been previously reported to be responsible for various CHDs, including ASD, ventricular septal defect, tetralogy of Fallot, pentalogy of Fallot, patent ductus arteriosus, common atrioventricular canal, double outlet right ventricle, coarctation of the aorta, total anomalous pulmonary venous connection and cardiac valvular malformation, with ASD being the most common phenotype (32,58-61). In the current study, ASD was documented in two family members carrying the TBX20 mutation, including a female adult who additionally presented with adult-onset DCM and her juvenile daughter had only ASD without DCM. These results highlighted the pivotal role of TBX20 in humans during cardiovascular development.

There were limitations to the present study. Firstly, due to the fact that other DCM-associated genes were not screened in this family, it was not possible to rule out the contribution of other mutant genes to the pathogenesis of the disease. In addition, due to lack of availability of tissue samples from the mutation carrier, it was not possible to verify the presence of NMD, although the occurrence of NMD yielded haploinefficiency, an effect identical to that of the functional characterization. Finally, more functional analyses, including analyses of subcellular distribution and the binding ability of the mutant TBX20 to target DNA molecules or other components in the transcriptional machinery, are required in order to explain why the mutant TBX20 lost transcriptional activity.
In conclusion, the current study associated TBX20 haploinefficiency with isolated DCM, and expanded upon the mutational spectrum of TBX20 associated with DCM and CHD, which provides novel insight into the molecular mechanism of DCM and CHD, suggesting potential implications for early personalized treatment of these diseases.

\section{Acknowledgements}

The authors would like to thank the participants for their participation in the current study. The present study was supported by grants from the National Natural Science Foundation of China (grant nos. 81270161 and 81470372), the Key Program for Basic Research of Shanghai, China (grant no. 14JC1405500) and the Natural Science Fund of Shanghai, China (grant no. 15ZR1438100).

\section{References}

1. Maron BJ, Towbin JA, Thiene G, Antzelevitch C, Corrado D, Arnett D, Moss AJ, Seidman CE, Young JB; American Heart Association, et al: Contemporary definitions and classification of the cardiomyopathies: An American Heart Association Scientific Statement from the Council on Clinical Cardiology, Heart Failure and Transplantation Committee; Quality of Care and Outcomes Research and Functional Genomics and Translational Biology Interdisciplinary Working Groups; and Council on Epidemiology and Prevention. Circulation 113: 1807-1816, 2006.

2. Garcia-Pavia P, Cobo-Marcos M, Guzzo-Merello G, Gomez-Bueno M, Bornstein B, Lara-Pezzi E, Segovia J and Alonso-Pulpon L: Genetics in dilated cardiomyopathy. Biomark Med 7: 517-533, 2013.

3. Chen W, Huo J, Ma A, Bai L and Liu P: A novel mutation of the LMNA gene in a family with dilated cardiomyopathy, conduction system disease, and sudden cardiac death of young females. Mol Cell Biochem 382: 307-311, 2013.

4. McNally EM, Golbus JR and Puckelwartz MJ: Genetic mutations and mechanisms in dilated cardiomyopathy. J Clin Invest 123: 19-26, 2013.

5. Agrawal PB, Pierson CR, Joshi M, Liu X, Ravenscroft G, Moghadaszadeh B, Talabere T, Viola M, Swanson LC, Haliloğlu G, et al: SPEG interacts with myotubularin, and its deficiency causes centronuclear myopathy with dilated cardiomyopathy. Am J Hum Genet 95: 218-226, 2014

6. Arndt AK, Schafer S, Drenckhahn JD, Sabeh MK, Plovie ER, Caliebe A, Klopocki E, Musso G, Werdich AA, Kalwa H, et al: Fine mapping of the 1p36 deletion syndrome identifies mutation of PRDM16 as a cause of cardiomyopathy. Am J Hum Genet 93: 67-77, 2013.

7. Haas J, Frese KS, Peil B, Kloos W, Keller A, Nietsch R, Feng Z, Müller S, Kayvanpour E, Vogel B, et al: Atlas of the clinical genetics of human dilated cardiomyopathy. Eur Heart J 36: 1123-1135a, 2015.

8. Reinstein E, Orvin K, Tayeb-Fligelman E, Stiebel-Kalish H, Tzur S, Pimienta AL, Bazak L, Bengal T, Cohen L, Gaton DD, et al: Mutations in TAX1BP3 cause dilated cardiomyopathy with septo-optic dysplasia. Hum Mutat 36: 439-442, 2015.

9. Wahbi K, Béhin A, Bécane HM, Leturcq F, Cossée M, Laforêt P, Stojkovic T, Carlier P, Toussaint M, Gaxotte V, et al: Dilated cardiomyopathy in patients with mutations in anoctamin 5. Int $\mathrm{J}$ Cardiol 168: 76-79, 2013.

10. Flack E and Kannankeril PJ: The genetics of dilated cardiomyopathy. Heart Rhythm 9: 397-398, 2012.

11. Pashmforoush M, Lu JT, Chen H, Amand TS, Kondo R, Pradervand S, Evans SM, Clark B, Feramisco JR, Giles W, et al: Nkx2-5 pathways and congenital heart disease; loss of ventricular myocyte lineage specification leads to progressive cardiomyopathy and complete heart block. Cell 117: 373-386, 2004.

12. Prall OW, Menon MK, Solloway MJ, Watanabe Y, Zaffran S, Bajolle F, Biben C, McBride JJ, Robertson BR, Chaulet H, et al: An Nkx2-5/Bmp2/Smad1 negative feedback loop controls heart progenitor specification and proliferation. Cell 128: 947-959, 2007. 
13. Pikkarainen S, Tokola H, Kerkelä R and Ruskoaho H: GATA transcription factors in the developing and adult heart. Cardiovasc Res 63: 196-207, 2004.

14. Greulich F, Rudat C and Kispert A: Mechanisms of T-box gene function in the developing heart. Cardiovasc Res 91: 212-222, 2011.

15. Oka T, Xu J and Molkentin JD: Re-employment of developmental transcription factors in adult heart disease. Semin Cell Dev Biol 18: 117-131, 2007.

16. Song K, Nam YJ, Luo X, Qi X, Tan W, Huang GN, Acharya A, Smith CL, Tallquist MD, Neilson EG, et al: Heart repair by reprogramming non-myocytes with cardiac transcription factors. Nature 485: 599-604, 2012.

17. McCulley DJ and Black BL: Transcription factor pathways and congenital heart disease. Curr Top Dev Biol 100: 253-277, 2012.

18. Stennard FA, Costa MW, Elliott DA, Rankin S, Haast SJ, Lai D, McDonald LP, Niederreither K, Dolle P, Bruneau BG, et al: Cardiac T-box factor Tbx20 directly interacts with Nkx2-5, GATA4, and GATA5 in regulation of gene expression in the developing heart. Dev Biol 262: 206-224, 2003.

19. Schott JJ, Benson DW, Basson CT, Pease W, Silberbach GM, Moak JP, Maron BJ, Seidman CE and Seidman JG: Congenital heart disease caused by mutations in the transcription factor NKX2-5. Science 281: 108-111, 1998.

20. Qu XK, Qiu XB, Yuan F, Wang J, Zhao CM, Liu XY, Zhang XL, Li RG, Xu YJ, Hou XM, et al: A novel NKX2.5 loss-of-function mutation associated with congenital bicuspid aortic valve. Am J Cardiol 114: 1891-1895, 2014.

21. Garg V, Kathiriya IS, Barnes R, Schluterman MK, King IN, Butler CA, Rothrock CR, Eapen RS, Hirayama-Yamada K, Joo K, et al: GATA4 mutations cause human congenital heart defects and reveal an interaction with TBX5. Nature 424 443-447, 2003

22. Yang YQ, Gharibeh L, Li RG, Xin YF, Wang J, Liu ZM, Qiu XB, $\mathrm{Xu} \mathrm{YJ}, \mathrm{Xu} \mathrm{L}, \mathrm{Qu} \mathrm{XK}$, et al: GATA4 loss-of-function mutations underlie familial tetralogy of Fallot. Hum Mutat 34: 1662-1671, 2013.

23. Xiang R, Fan LL, Huang H, Cao BB, Li XP, Peng DQ and Xia K: A novel mutation of GATA4 (K319E) is responsible for familial atrial septal defect and pulmonary valve stenosis. Gene 534 320-323, 2014

24. Wei D, Bao H, Liu XY, Zhou N, Wang Q, Li RG, Xu YJ and Yang YQ: GATA5 loss-of-function mutations underlie tetralogy of fallot. Int J Med Sci 10: 34-42, 2013.

25. Wei D, Bao H, Zhou N, Zheng GF, Liu XY and Yang YQ: GATA5 loss-of-function mutation responsible for the congenital ventriculoseptal defect. Pediatr Cardiol 34: 504-511, 2013 .

26. Shi LM, Tao JW, Qiu XB, Wang J, Yuan F, Xu L, Liu H, Li RG, Xu YJ, Wang Q, et al: GATA5 loss-of-function mutations associated with congenital bicuspid aortic valve. Int J Mol Med 33: $1219-1226,2014$

27. Huang RT, Xue S, Xu YJ, Zhou M and Yang YQ: Somatic GATA5 mutations in sporadic tetralogy of Fallot. Int J Mol Med 33: 1227-1235, 2014

28. Wang X, Ji W, Wang J, Zhao P, Guo Y, Xu R, Chen S and Sun K: Identification of two novel GATA6 mutations in patients with nonsyndromic conotruncal heart defects. Mol Med Rep 10: 743-748, 2014

29. Huang RT, Xue S, Xu YJ and Yang YQ: Somatic mutations in the GATA6 gene underlie sporadic tetralogy of Fallot. Int J Mol Med 31: 51-58, 2013.

30. Baban A, Postma AV, Marini M, Trocchio G, Santilli A, Pelegrini M, Sirleto P, Lerone M, Albanese SB, Barnett P, et al: Identification of TBX5 mutations in a series of 94 patients with tetralogy of Fallot. Am J Med Genet A 164A: 3100-3107, 2014.

31. Al-Qattan MM and Abou Al-Shaar H: Molecular basis of the clinical features of Holt-Oram syndrome resulting from missense and extended protein mutations of the TBX5 gene as well as TBX5 ntragenic duplications. Gene 560: 129-136, 2015.

32. Pan Y, Geng R, Zhou N, Zheng GF, Zhao H, Wang J, Zhao CM, Qiu XB, Yang YQ and Liu XY: TBX20 loss-of-function mutation contributes to double outlet right ventricle. Int J Mol Med 35: 1058-1066, 2015.

33. Andersen TA, Troelsen Kde L and Larsen LA: Of mice and men: Molecular genetics of congenital heart disease. Cell Mol Life Sci 71: 1327-1352, 2014
34. Huang RT, Xue S, Xu YJ, Zhou M and Yang YQ: A novel NKX2.5 loss-of-function mutation responsible for familial atrial fibrillation. Int J Mol Med 31: 1119-1126, 2013.

35. Xie WH, Chang C, Xu YJ, Li RG, Qu XK, Fang WY, Liu X and Yang YQ: Prevalence and spectrum of Nkx2.5 mutations associated with idiopathic atrial fibrillation. Clinics (Sao Paulo) 68: 777-784, 2013.

36. Yu H, Xu JH, Song HM, Zhao L, Xu WJ, Wang J, Li RG, Xu L, Jiang WF, Qiu XB, et al: Mutational spectrum of the NKX2-5 gene in patients with lone atrial fibrillation. Int J Med Sci 11: 554-563, 2014.

37. Perera JL, Johnson NM, Judge DP and Crosson JE: Novel and highly lethal NKX2.5 missense mutation in a family with sudden death and ventricular arrhythmia. Pediatr Cardiol 35: 1206-1212, 2014.

38. Wang XH, Huang CX, Wang Q, Li RG, Xu YJ, Liu X, Fang WY and Yang YQ: A novel GATA5 loss-of-function mutation underlies lone atrial fibrillation. Int J Mol Med 31: 43-50, 2013.

39. Postma AV, van de Meerakker JB, Mathijssen IB, Barnett $P$, Christoffels VM, Ilgun A, Lam J, Wilde AA, Lekanne Deprez RH and Moorman AF: A gain-of-function TBX5 mutation is associated with atypical Holt-Oram syndrome and paroxysmal atrial fibrillation. Circ Res 102: 1433-1442, 2008.

40. Hong K and Xiong Q: Genetic basis of atrial fibrillation. Curr Opin Cardiol 29: 220-226, 2014.

41. Costa MW, Guo G, Wolstein O, Vale M, Castro ML, Wang L, Otway R, Riek P, Cochrane N, Furtado M, et al: Functional characterization of a novel mutation in NKX2-5 associated with congenital heart disease and adult-onset cardiomyopathy. Circ Cardiovasc Genet 6: 238-247, 2013

42. Yuan F, Qiu XB, Li RG, Qu XK, Wang J, Xu YJ, Liu X, Fang WY, Yang YQ and Liao DN: A novel NKX2-5 loss-of-function mutation predisposes to familial dilated cardiomyopathy and arrhythmias. Int J Mol Med 35: 478-486, 2015.

43. Li RG, Li L, Qiu XB, Yuan F, Xu L, Li X, Xu YJ, Jiang WF, Jiang JQ, Liu X, et al: GATA4 loss-of-function mutation underlies familial dilated cardiomyopathy. Biochem Biophys Res Commun 439: 591-596, 2013

44. Zhao L, Xu JH, Xu WJ, Yu H, Wang Q, Zheng HZ, Jiang WF, Jiang JF and Yang YQ: A novel GATA4 loss-of-function mutation responsible for familial dilated cardiomyopathy. Int J Mol Med 33: 654-660, 2014

45. Li J, Liu WD, Yang ZL, Yuan F, Xu L, Li RG and Yang YQ: Prevalence and spectrum of GATA4 mutations associated with sporadic dilated cardiomyopathy. Gene 548: 174-181, 2014.

46. Zhang XL, Dai N, Tang K, Chen YQ, Chen W, Wang J, Zhao CM, Yuan F, Qiu XB, Qu XK, et al: GATA5 loss-of-function mutation in familial dilated cardiomyopathy. Int J Mol Med 35: 763-770, 2015.

47. Xu L, Zhao L, Yuan F, Jiang WF, Liu H, Li RG, Xu YJ, Zhang M, Fang WY, Qu XK, et al: GATA6 loss-of-function mutations contribute to familial dilated cardiomyopathy. Int J Mol Med 34: 1315-1322, 2014.

48. Zhang XL, Qiu XB, Yuan F, Wang J, Zhao CM, Li RG, Xu L, Xu YJ, Shi HY, Hou XM, et al: TBX5 loss-of-function mutation contributes to familial dilated cardiomyopathy. Biochem Biophys Res Commun 459: 166-171, 2015.

49. Zhou W, Zhao L, Jiang JQ, Jiang WF, Yang YQ and Qiu XB: A novel TBX5 loss-of-function mutation associated with sporadic dilated cardiomyopathy. Int J Mol Med 36: 282-288, 2015.

50. Akazawa $\mathrm{H}$ and Komuro I: Cardiac transcription factor $\mathrm{Csx} / \mathrm{Nkx}$ 2-5: Its role in cardiac development and diseases. Pharmacol Ther 107: 252-268, 2005.

51. Kervestin S and Jacobson A: NMD: A multifaceted response to premature translational termination. Nat Rev Mol Cell Biol 13: 700-712, 2012.

52. Keeling KM and Bedwell DM: Suppression of nonsense mutations as a therapeutic approach to treat genetic diseases. Wiley Interdiscip Rev RNA 2: 837-852, 2011

53. Kirk EP, Sunde M, Costa MW, Rankin SA, Wolstein O, Castro ML, Butler TL, Hyun C, Guo G, Otway R, et al: Mutations in cardiac T-box factor gene TBX20 are associated with diverse cardiac pathologies, including defects of septation and valvulogenesis and cardiomyopathy. Am J Hum Genet 81: 280-291, 2007.

54. Qian L, Mohapatra B, Akasaka T, Liu J, Ocorr K, Towbin JA and Bodmer R: Transcription factor neuromancer/TBX20 is required for cardiac function in Drosophila with implications for human heart disease. Proc Natl Acad Sci USA 105: 19833-19838, 2008 
55. Zhao CM, Bing-Sun, Song HM, Wang J, Xu WJ, Jiang JF, Qiu XB, Yuan F, Xu JH and Yang YQ: TBX20 loss-of-function mutation associated with familial dilated cardiomyopathy. Clin Chem Lab Med 54: 325-332, 2016.

56. Shen T, Aneas I, Sakabe N, Dirschinger RJ, Wang G, Smemo S, Westlund JM, Cheng H, Dalton N, Gu Y, et al: Tbx20 regulates a genetic program essential to adult mouse cardiomyocyte function. J Clin Invest 121: 4640-4654, 2011.

57. Shen T, Yang C, Ding L, Zhu Y, Ruan Y, Cheng H, Qin W, Huang X, Zhang H, Man Y, et al: Tbx20 functions as an important regulator of estrogen-mediated cardiomyocyte protection during oxidative stress. Int J Cardiol 168: 3704-3714, 2013.

58. Liu C, Shen A, Li X, Jiao W, Zhang X and Li Z: T-box transcription factor TBX20 mutations in Chinese patients with congenital heart disease. Eur J Med Genet 51: 580-587, 2008.
59. Posch MG, Gramlich M, Sunde M, Schmitt KR, Lee SH, Richter S, Kersten A, Perrot A, Panek AN, Al Khatib IH, et al: A gain-of-function TBX20 mutation causes congenital atrial septal defects, patent foramen ovale and cardiac valve defects. J Med Genet 47: 230-235, 2010.

60. Liu JJ, Fan LL, Chen JL, Tan ZP and Yang YF: A novel variant in TBX20 (p.D176N) identified by whole-exome sequencing in combination with a congenital heart disease related gene filter is associated with familial atrial septal defect. J Zhejiang Univ Sci B 15: 830-837, 2014.

61. Monroy-Muñoz IE, Pérez-Hernández N, Rodríguez-Pérez JM, Muñoz-Medina JE, Angeles-Martínez J, García-Trejo JJ, Morales-Ríos E, Massó F, Sandoval-Jones JP, Cervantes-Salazar J, et al: Novel mutations in the transcriptional activator domain of the human TBX20 in patients with atrial septal defect. Biomed Res Int 2015: 718786, 2015. 